\title{
Desempenho agronômico de clones elite de batata
}

\author{
Giovani O da Silva ${ }^{1}$; Caroline M Castro² ${ }^{2}$ Laerte R Terres²; Angela Rohr²; Fábio A Suinaga ${ }^{3}$; Arione da S \\ Pereira $^{2}$ \\ ${ }^{1}$ Embrapa Hortaliças-SNT, C. Postal 317,89460-000 Canoinhas-SC; giovaniolegario@gmail.com (autor correspondente); ${ }^{2}$ Embrapa \\ Clima Temperado, C. Postal 403, 96001-970 Pelotas-RS; caroline.castro@cpact.embrapa.br, laerte_terres@yahoo.com.br, angelbio10@ \\ yahoo.com.br, arione.pereira@cpact.embrapa.br; ${ }^{3}$ Embrapa Hortaliças, C. Postal 218 70359-970 Brasília-DF, fabio@cnph.embrapa.br
}

\section{RESUMO}

O objetivo do presente trabalho foi verificar o desempenho de oito clones elite de batata quanto ao ciclo vegetativo, caracteres de produção e peso específico em comparação com as cultivares mais utilizadas no país. O experimento foi realizado no campo experimental da Embrapa Clima Temperado, Pelotas (RS). Foram avaliados oito clones elite desenvolvidos pelo Programa de Melhoramento Genético de Batata da Embrapa juntamente com duas cultivares comerciais, no cultivo de outono de 2011. O delineamento experimental foi em blocos casualizados com quatro repetições e parcelas compostas de uma linha com 20 plantas. Aos 95 dias após o plantio determinou-se o ciclo vegetativo dos genótipos e aos 110 dias foram realizadas a colheita e avaliações dos componentes de produção e peso específico. Após a verificação da normalidade de distribuição dos erros, os dados foram submetidos à análise de variância e de agrupamento de médias por Scott \& Knott. Os clones CL02-05, CL69-05, CL27-05 e 2197-15 apresentaram maiores número de tubérculos comerciais, percentagem de tubérculos comerciais e massa média de tubérculos que as cultivares testemunhas. O clone CL02-05 revelou, além disso, o maior potencial de produção de tubérculos comerciais dentre os quatro clones. Os clones CL69-05 e 2197-15 apresentaram peso específico e ciclo vegetativo semelhantes à Asterix e também maior potencial produtivo.

Palavras-chave: Solanun tuberosum, massa de tubérculos, ciclo vegetativo, peso específico.

\begin{abstract}
Agronomic performance of elite potato clones

The aim of this work was to verify the growth cycle, yield components and specific gravity of advanced potato clones as compared to the main varieties grown in Brazil. The experiment was carried on at the Embrapa Clima Temperado experimental field, in Pelotas, Rio Grande do Sul state, Brazil. Eight advanced potato clones developed by the Embrapa Potato Breeding Program, and two commercial cultivars were evaluated in the autumn season of 2011. A randomized complete block design with four replications was used, the plots being constituted by a line of 20 plants. Growth cycle was assessed 95 days after planting. Plants of each plot were harvested at 110 days, followed by evaluation of yield components and specific gravity. After checking for normality of error distribution, the data were submitted to analysis of variance and to means grouping by the Scott \& Knott test. CL02-05, CL69-05, CL27-05 and 2197-15 clones showed higher commercial tuber number, percentage of commercial tubers and average tuber weight than the check varieties. CL02-05 clone showed, besides, the highest yield potential of commercial tubers of all four clones. CL69-05 and 2197-15 presented specific gravity and growth cycle similar to Asterix, but had higher yield potential and larger tuber size than it.
\end{abstract}

Keywords: Solanun tuberosum, yield, growth cycle, specific gravity.

\section{(Recebido para publicação em 20 de dezembro de 2011; aceito em 3 de agosto de 2012) (Received on December 20, 2011; accepted on August 3, 2012)}

\begin{abstract}
A maioria das cultivares de batata utilizadas no Brasil são de origem europeia e sofrem os efeitos adversos das temperaturas mais elevadas (Menezes et al., 2001) e do fotoperíodo mais curto, ocasionando redução do ciclo vegetativo e do potencial produtivo (Kooman \& Rabbinge, 1996). Para suplantar esta dificuldade, torna-se necessária elevada quantidade de insumos para se ter uma produção razoável, ocasionando assim um decréscimo na sustentabilidade dos cultivos. É sabido que, em regiões temperadas, que as cultivares de ciclo longo ( $>130$ dias) são mais produtivas que os genótipos precoces ( $<100$ dias). Isto também tem sido verificado nas condições tropicais, onde clones com
\end{abstract}

ciclo mais tardio são mais produtivos que os mais precoces, sugerindo que a seleção de clones tardios constitui-se em estratégia para aumentar a produtividade da cultura (Silva \& Pinto, 2005; Rodrigues et al., 2009).

Por outro lado, os produtores preferem cultivares mais precoces (Dias et al., 2003; Rodrigues et al., 2009), por estas possibilitarem maior número de cultivos por ano, menor tempo de exposição das plantas a intempéries, menor risco de doenças e pragas, e demanda de irrigação. Além disso, podem proporcionar a opção de colheita antecipada dependendo de cotação do produto no mercado. Sendo assim, a avaliação do ciclo vegetativo, adicionalmente aos caracteres componentes do rendimento, é importante para os programas de melhoramento, sendo necessária a seleção de clones produtivos e precoces.

Quanto aos componentes de rendimento, sabe-se que plantas que apresentam elevado número de tubérculos apresentam, geralmente, tubérculos menores. Desta forma, é importante a seleção buscando o equilíbrio entre número e tamanho de tubérculos. Tanto o número quanto o tamanho dos tubérculos influenciam diretamente o rendimento de tubérculos comerciais (Silva et al., 2006).

O peso específico é outro caráter importante, pois é diretamente relacionado com o teor de matéria seca nos tubér- 
culos, sendo de interesse em cultivares de batata para processamento na forma frita (Schippers, 1976). Maior peso específico proporciona ao produto final maior rendimento na industrialização e menor absorção de gordura durante a fritura, além de melhorias na textura e no sabor (Smith, 1975).

A obtenção de cultivares nacionais adaptadas às condições de cultivo das regiões brasileiras produtoras e resistentes às principais doenças é a alternativa mais viável para tornar a cultura mais produtiva e rentável para o produtor (Gadum et al., 2003). O grande desafio dos melhoristas de batata consiste em disponibilizar permanentemente cultivares que atendam às exigências dos consumidores, que cada vez mais priorizam produtos de qualidade (visuais e culinárias), dos produtores (maior rendimento aliado à precocidade) e das indústrias (qualidade industrial). Portanto, estudos que permitam o melhor conhecimento da expressão destes caracteres frente às condições ambientais e a verificação da potencialidade de clones para se tornarem cultivares, são importantes para a cultura da batata no Brasil.

O objetivo do presente trabalho foi verificar o desempenho de oito clones elite de batata quanto ao ciclo vegetativo, caracteres de produção e peso específico em comparação com as cultivares mais utilizadas no país.

\section{MATERIAL E MÉTODOS}

$\mathrm{O}$ experimento foi realizado no campo experimental da Embrapa Clima Temperado, em Pelotas (31 $42^{\prime} \mathrm{S}$, $\left.52^{\circ} 24^{\prime} \mathrm{W}\right)$, em 2011. Foram avaliados oito clones elite pertencentes ao programa de melhoramento genético da Embrapa (CL83-05, CL135-06, CL123-05, CL27-05, CL69-05, 2197-15, CL10705, CL02-05), em comparação com as cultivares testemunha Agata e Asterix.

O delineamento experimental foi em blocos casualizados com quatro repetições, cada parcela foi composta de uma linha de seis metros com 20 plantas. Os tubérculos foram plantados espaçados em $80 \mathrm{~cm}$ entre linhas e $30 \mathrm{~cm}$ dentro da linha, em 16 de março de 2011. Como fertilizantes foram utilizadas $2 \mathrm{t} / \mathrm{ha}$ da fórmula comercial 5-30-10, e os tratos culturais e fitossanitários seguiram as recomendações da região (Pereira, 2010).

Aos 95 dias após o plantio determinou-se o ciclo vegetativo das plantas de cada parcela, com atribuição visual de notas com números inteiros variando de 1 (tardia) a 9 (precoce), segundo metodologia adaptada de Brasil (1997).

Após a senescência das plantas, aos 110 dias após o plantio foi realizada a colheita. Foram avaliados os caracteres número de tubérculos comerciais por parcela (NTC), diâmetro acima de 45 mm e sem defeitos fisiológicos; número total de tubérculos por parcela (NTT); massa de tubérculos comerciais (MTC), em kg/parcela; massa total de tubérculos (MTT), em kg/parcela; percentagem de tubérculos comerciais (\%TC), obtida pela divisão do número de tubérculos comerciais e o número total de tubérculos, multiplicado por 100; massa média de tubérculos (MMT) em g/parcela, obtida pela divisão da massa total e o número total de tubérculos e peso específico (PE), utilizando o método do peso na água e peso no ar (Pereira et al., 2008).

Os dados de cada caráter avaliado foram verificados quanto à distribuição normal dos erros por meio do teste de Lilliefors, submetidos à análise de variância e de agrupamento de médias pelo teste de Scott \& Knott, com a utilização do programa GENES (Cruz, 2006).

\section{RESULTADOS E DISCUSSÃO}

Todos os caracteres apresentaram distribuição normal dos erros. A análise de variância revelou que todos os caracteres avaliados apresentaram diferenças significativas $(\mathrm{p}<0,05)$, possibilitando diferenciar os clones e as cultivares. Os coeficientes de variação variaram de $0,54 \%$ para peso específico a $20,70 \%$ para massa de tubérculos comerciais (Tabela 1), indicando boa precisão experimental. Estes valores são semelhantes aos obtidos por Silva et al. (2006), com valores variando de 17,31 a 21,03 para os caracteres rendimento, número e massa média de tubérculos de batata. Semelhantes também aos verificados por Bisognin et al. (2008), variando entre 16,19 e 25,60 para o caractere rendimento de tubérculos de clones de batata com diferentes tamanhos. Da mesma forma, Costa et al. (2007) citaram valores de 22,70 e 18,30 para rendimento total e número total de tubérculos de clones de batata.

A relação coeficiente de variação genética / coeficiente de variação ambiental $(\mathrm{CVg} / \mathrm{CVe})$ foi superior à unidade para todos os caracteres, indicando que a variação de ordem genética superou a ambiental e que a seleção baseada nestes caracteres seria eficiente. Silva et al. (2006) verificaram superioridade do valor do coeficiente de variação ambiental para caracteres relacionados ao rendimento de tubérculos de batata. De maneira semelhante, para o caractere produção total, Neder et al. (2010) verificaram que na média de quatro experimentos realizados com clones de batata o $\mathrm{CV}$ foi de $38,50 \%$, enquanto que o $\mathrm{CVg}$ foi de $27,16 \%$. Da mesma forma, Simon et al. (2009) verificaram valores da relação $\mathrm{CVg} / \mathrm{CVe}$ variando de 0,72 a 0,82 para o caractere produção de tubérculos por planta. Pois o rendimento de tubérculos de batata é um caractere quantitativo e normalmente sofre grande influência ambiental (Silva et al., 2006).

Quanto às médias de ciclo vegetativo, os clones formaram três grupos (Tabela 1). O grupo precoce foi constituído unicamente pela testemunha Agata, enquanto o grupo de ciclo médio foi composto pelos clones CL02-05, C2705 e CL107-05, e o grupo classificado como de ciclo tardio foi formado pelos demais clones e a cultivar testemunha Asterix. As classificações de ciclo das duas testemunhas conferem com as suas conhecidas descrições (Nivap, 2007).

No tocante ao número total de tubérculos por parcela (NTT), a cultivar testemunha Agata apresentou o maior número de tubérculos, enquanto os clones CL123-05 e CL83-05, juntamente com a testemunha Asterix demonstraram reduzido número de tubérculos, já os demais clones classificaram-se como intermediários para número de tubérculos. Em relação ao número de tubérculos comerciais (NTC) produzidos por parcela, os clones CL27-05, CL02-05, 2197-15 e CL69-05 formaram o grupo superior, enquanto os clones 
Tabela 1. Médias para ciclo vegetativo, componentes de produção e peso específico de oito clones e duas cultivares de batata avaliados em 2011 (means for yield components and specific gravity of eight clones and two potato cultivars grown in 2011). Pelotas, Embrapa Clima Temperado, 2011.

\begin{tabular}{lcccrrrrr}
\hline Clone & Ciclo $^{2}$ & NTC & \multicolumn{1}{c}{ NTT } & \multicolumn{1}{c}{ MTC } & MT & TC (\%) & \multicolumn{1}{c}{ MMT } & PE \\
\hline Agata & $8,25 \mathrm{a}^{1}$ & $68,25 \mathrm{~b}$ & $176,75 \mathrm{a}$ & $7383,75 \mathrm{c}$ & $10460,00 \mathrm{c}$ & $41,53 \mathrm{c}$ & $63,03 \mathrm{c}$ & $1,062 \mathrm{c}$ \\
CL107-05 & $6,75 \mathrm{~b}$ & $61,00 \mathrm{~b}$ & $140,25 \mathrm{~b}$ & $7662,50 \mathrm{c}$ & $10462,50 \mathrm{c}$ & $43,33 \mathrm{c}$ & $74,18 \mathrm{c}$ & $1,076 \mathrm{~b}$ \\
CL27-05 & $6,25 \mathrm{~b}$ & $92,25 \mathrm{a}$ & $128,75 \mathrm{~b}$ & $12063,75 \mathrm{~b}$ & $13195,00 \mathrm{~b}$ & $71,88 \mathrm{a}$ & $103,13 \mathrm{a}$ & $1,078 \mathrm{~b}$ \\
CL02-05 & $6,00 \mathrm{~b}$ & $91,50 \mathrm{a}$ & $130,25 \mathrm{~b}$ & $15467,50 \mathrm{a}$ & $16573,75 \mathrm{a}$ & $70,18 \mathrm{a}$ & $126,88 \mathrm{a}$ & $1,068 \mathrm{c}$ \\
CL123-05 & $5,50 \mathrm{c}$ & $45,50 \mathrm{~b}$ & $80,25 \mathrm{c}$ & $5968,75 \mathrm{c}$ & $7245,00 \mathrm{c}$ & $56,78 \mathrm{~b}$ & $90,33 \mathrm{~b}$ & $1,075 \mathrm{~b}$ \\
$2197-15$ & $5,00 \mathrm{c}$ & $87,00 \mathrm{a}$ & $114,00 \mathrm{~b}$ & $11987,50 \mathrm{~b}$ & $12772,50 \mathrm{~b}$ & $75,98 \mathrm{a}$ & $111,68 \mathrm{a}$ & $1,088 \mathrm{a}$ \\
CL135-06 & $5,00 \mathrm{c}$ & $58,25 \mathrm{~b}$ & $118,25 \mathrm{~b}$ & $6411,25 \mathrm{c}$ & $8701,25 \mathrm{c}$ & $49,50 \mathrm{c}$ & $73,68 \mathrm{c}$ & $1,077 \mathrm{~b}$ \\
CL69-05 & $4,75 \mathrm{c}$ & $91,75 \mathrm{a}$ & $119,00 \mathrm{~b}$ & $13288,75 \mathrm{~b}$ & $14021,25 \mathrm{~b}$ & $78,05 \mathrm{a}$ & $119,70 \mathrm{a}$ & $1,085 \mathrm{a}$ \\
CL83-05 & $4,75 \mathrm{c}$ & $56,25 \mathrm{~b}$ & $96,25 \mathrm{c}$ & $7175,00 \mathrm{c}$ & $8636,25 \mathrm{c}$ & $58,20 \mathrm{~b}$ & $89,65 \mathrm{~b}$ & $1,069 \mathrm{c}$ \\
Asterix & $4,75 \mathrm{c}$ & $48,50 \mathrm{~b}$ & $82,00 \mathrm{c}$ & $6356,25 \mathrm{c}$ & $7588,75 \mathrm{c}$ & $58,75 \mathrm{~b}$ & $92,35 \mathrm{~b}$ & $1,082 \mathrm{a}$ \\
\hline CV $(\%)$ & 12,67 & 16,25 & 15,96 & 20,70 & 17,19 & 16,69 & 15,62 & 0,54 \\
CVg/CVe & 1,50 & 1,58 & 1,27 & 1,71 & 1,31 & 1,60 & 1,33 & 1,27 \\
\hline
\end{tabular}

Médias $^{1}$ seguidas pela mesma letra, em cada coluna, pertencem ao mesmo grupo pelo critério de Scott-Knott ao nível de 5\% de probabilidade de erro. ${ }^{2} \mathrm{Ciclo}=$ ciclo vegetativo (notas de 1 (tardia) a 9 (precoce)); NTC $=$ número de tubérculos comerciais por parcela; NTT= número total de tubérculos por parcela; MTC = massa de tubérculos comerciais por parcela $(\mathrm{kg} /$ parcela $)$; MT= massa total de tubérculos por parcela $\left(\mathrm{kg} /\right.$ parcela); $\mathrm{TC}(\%)=$ tubérculos comerciais $(\%) ; \mathrm{MMT}=$ massa média de tubérculo $\left(\mathrm{g} /\right.$ parcela); PE= peso específico; (means ${ }^{1}$ followed by the same letter, in each column, do not differ significantly among them by the Scott-Knott test at $5 \%$ of probability of error. ${ }^{2} \mathrm{Ciclo}=$ growth cycle (grades from 1 (late maturity) to 9 (early maturity)); NTC= number of commercial tubers per plot; NTT= total tuber number per plot; $\mathrm{MTC}=$ commercial tuber yield per plot $(\mathrm{kg} / \mathrm{plot}) ; \mathrm{MT}=$ total tuber yield per plot $(\mathrm{kg} / \mathrm{plot}) ; \mathrm{TC}(\%)=$ commercial tubers $(\%)$; $\mathrm{MMT}=\mathrm{average}$ tuber weight (g/plot); $\mathrm{PE}=$ specific gravity).

CL107-05, CL123-05 e CL135-06, e as duas cultivares testemunhas formaram o grupo intermediário.

Quanto à massa de tubérculos, total (MT) e comercial (MTC), o clone CL0205 constituiu individualmente o grupo mais produtivo; os clones CL27-05, 2197-15 e CL69-05, o grupo intermediário, mas superior às duas testemunhas, as quais juntamente com os clones CL10705, CL123-05, CL135-06 e CL83-05 classificaram-se no grupo inferior. Em relação à percentagem de tubérculos comerciais (\%TC), destacaram-se os clones CL27-05, CL02-05, 2197-15 e CL69-05. Os clones CL123-05 e CL83-05, juntamente com a testemunha Asterix, apresentaram desempenho intermediário, enquanto Agata e os demais clones constituíram com menor percentual de tubérculos comerciais. Quanto à massa média de tubérculo (MMT), os clones CL27-05, CL02-05, 2197-15 e CL69-05 classificaram-se no grupo superior; CL123-05, CL8305 e Asterix, no grupo intermediário, e os demais clones juntamente com a testemunha Agata, apresentaram menor massa média.

Em relação ao peso específico (PE), os clones 2197-15 e CL69-05, e a teste- munha Asterix apresentaram os maiores valores; os clones CL107-05, CL27-05, CL123-05 e CL135-06, apresentaram valores intermediários; e os demais clones juntamente com a testemunha Agata constituíram o grupo de menor peso específico. A classificação da testemunha Asterix no grupo de peso específico mais elevado está de acordo com a característica desta, que é utilizada em larga escala pela indústria na elaboração de palitos pré-fritos e, além disso, apresenta teor relativamente baixo de açúcares redutores (Nivap, 2007). Considerando-se o peso específico, os clones CL69-05 e 2197-15 apresentam potencialidade para uso na forma frita. Os valores de peso específico para as testemunhas deste estudo foram semelhantes aos obtidos por Pereira et al. (2008) com 1,062 e 1,070 para Agata e Asterix, respectivamente. Pode-se observar uma clara relação entre os caracteres peso específico e o ciclo vegetativo, onde os clones com maior peso específico classificaram-se no grupo tardio, e o mais precoce (testemunha Agata) esteve no grupo com menor peso específico. Estes resultados indicam que genótipos de batata mais tardios tendem a acumular mais matéria seca do que os precoces. Provavelmente devido ao maior tempo para realização de fotossíntese, o que pode ocasionar também maior produtividade (Silva \& Pinto, 2005; Silva et al., 2009).

Desta forma, pode-se verificar que os clones CL02-05, CL69-05, CL27-05 e 2197-15 produziram maior número de tubérculos comerciais, percentagem de tubérculos comerciais e massa média de tubérculos que as cultivares testemunhas. O clone CL02-05 também demonstrou superioridade aos demais clones em relação à massa de tubérculos com tamanho comercial, sendo $100 \%$ superior à produtividade da melhor testemunha (Agata). Portanto, este foi o clone de melhor desempenho entre todos os genótipos avaliados neste estudo. Entretanto, o baixo peso específico sugere sua inaptidão ao uso na forma frita. Os clones CL69-05 e 2197-15 apresentam peso específico e ciclo vegetativo semelhantes à cultivar Asterix e também grande potencial produtivo.

\section{AGRADECIMENTOS}

Ao CNPq pelo auxilio financeiro ao Programa de Melhoramento Genético de Batata da Embrapa. 


\section{REFERÊNCIAS}

BISOGNIN DA; MÜLLER DR; STRECK NA; ANDRIOLO JL; SAUSEN D. 2008. Desenvolvimento e rendimento de clones de batata na primavera e no outono. Pesquisa Agropecuária Brasileira 43: 699-705.

BRASIL. 1997. Decreto $\mathrm{n}^{0} 2.366$, de 5 de novembro de 1997. Regulamenta a proteção de cultivares e os descritores das primeiras oito espécies que serão protegidas: algodão, arroz, batata, feijão, milho, soja, sorgo e trigo. Biotecnologia Ciência \& Desenvolvimento 1: 23-32.

COSTA LC; BISOGNIN DA; ANDRIOLO JL; RITTER CEL; BANDINELLI MG. 2007. Identificação de clones de batata com potencial para mesa e adaptados para os cultivos de outono e primavera do Rio Grande do Sul. Ciência e Natura 29: 93-104.

CRUZ CD. 2006. Programa genes: aplicativo computacional em genética e estatística. Viçosa; UFV. 648p.

DIAS GS; SILVA EC; MACIEL GM. 2003. Competição de cultivares de batata na Região de Alfenas-MG. In: CONGRESSO BRASILEIRO DE OLERICULTURA, 43. Resumos... Recife: SOB (CD-ROM).

GADUM J; PINTO CABP; RIOS MCD. 2003. Desempenho agronômico e reação de clones de batata (Solanum tuberosum L.) ao PVY.
Ciência e Agrotecnologia 27: 1484-1492.

KOOMAN PL; RABBINGE R. 1996. An analysis of the relation between dry matter allocation to the tuber and earliness of a potato crop. Annals of Botany 77: 235-242.

MENEZES CB; PINTO CABP; NURMBERG PL; LAMBERT ES. 2001. Combining ability of potato genotypes for cool and warm seasons in Brazil. Crop Breeding and Applied Biotechnology 1: 145-157.

NEDER DG; PINTO CABP; MELO DS; LEPRE AL; PEIXOUTO LS. 2010. Seleção de clones de batata com resistência múltipla à pinta preta e aos vírus X e Y. Ciência Rural 40: 1702-1708.

NIVAP - Netherlands Potato Consultative Foundation. 2007. Netherlands catalogue of potato varieties. Van Stolkweg: Nivap. 287p.

PEREIRA AS. (org). 2010. Produção de batata no Rio Grande do Sul. Sistema de Produção, 19. Pelotas: Embrapa Clima Temperado. 95p.

PEREIRAAS; NEY VG; TERRES LR; TREPTOW RO; CASTRO LAS. 2008. Caracteres de produção e qualidade de clones de batata selecionados de população segregante para resistência ao vírus $\mathrm{Y}$ da batata. Boletim de Pesquisa e Desenvolvimento, 67. Pelotas: Embrapa Clima Temperado. 18p.

RODRIGUES GB; PINTO CAB; BENITES FRG; MELO DS. 2009. Seleção para duração do ciclo vegetativo em batata e relação com a produtividade de tubérculos. Horticultura Brasileira 27: 280-285.

SCHIPPERS PA. 1976. The relationship between specific gravity and percentage of dry matter in potato tubers. American Potato Journal 53: 111-122.

SILVA LAS; PINTO CABP. 2005. Duration of the growth cycle and the yield potential of potato genotypes. Crop Breeding and Applied Biotechnology 5: 20-28.

SILVA FL; PINTO CABP; ALVES D; BENITES FRG; ANDRADE CM; RODRIGUES GB; LEPRE AL; BHERING LP. 2009. Caracterização morfofisiológica de clones precoces e tardios de batata visando à adaptação a condições tropicais. Bragantia 68: 295-302.

SILVA GO; SOUZA VQ; PEREIRA AS; CARVALHO FIF; FRITSCHE-NETO R. 2006. Early generation selection for tuber appearance affects potato yield components. Crop Breeding and Applied Biotechnology 6: 73-78.

SIMON GA; PINTO CABP; LAMBERT ES; ANDREU MA. 2009. Seleção de clones de batata resistentes à pinta preta e tolerantes ao calor. Ceres 56: 31-37.

SMITH O. 1975. Potato chips. In: TALBURT WF; SMITH O. (ed). Potato processing. Westport: AVI, 3rd ed: 305-402. 